\title{
The Clinical Conundrum of Managing Ischemic Stroke in Patients with Immune Thrombocytopenia
}

\author{
Anas Alrohimi (iD, Kaylynn Purdy (1D, Mustafa Alqarni, Ghazi Alotaibi, \\ Gregg Blevins, Ken Butcher, Jeremy Rempel, Cynthia Wu, Haowei Linda Sun, \\ Khurshid Khan
}

\begin{abstract}
Guidelines are lacking for management of acute ischemic stroke and stroke prevention in patients with immune thrombocytopenia (ITP). Our aim is to highlight the dilemma inherent in managing patients with both significant bleeding and thrombotic risk factors. In this review, we present two patients with history of ITP who presented with acute ischemic stroke and received tissue plasminogen activator (tPA) and endovascular thrombectomy (EVT), a rare management strategy in this patient population. In addition, we identified 27 case reports of ischemic stroke in patients with ITP; none of them received tPA or EVT. Furthermore, there are 92 patients with significant thrombocytopenia with no available data regarding the cause of thrombocytopenia, who were acutely treated with tPA or EVT. Conclusive evidence cannot be determined based on these limited number of cases. Future multicenter prospective cohort studies in patients with ITP are needed to provide better evidence-based treatment plans. At present, treatment of acute ischemic stroke in patients with ITP requires close collaboration between hematology and vascular neurology experts to find a balance between the benefit and risk of hemorrhagic complications.
\end{abstract}

RÉSUMÉ : La prise en charge de patients atteints de thrombopénie immune qui ont été victimes d'un AVC ischémique : une énigme clinique. Les cliniciens sont à court de lignes directrices quand il est question de prise en charge et de prévention dans le cas de patients atteints de thrombopénie immune (TPI) qui ont été victimes d'un AVC aigu. Notre objectif est ici de mettre en évidence le dilemme inhérent à la prise en charge de patients présentant à la fois des facteurs de risque hémorragique et thrombotique importants. Nous entendons donc présenter dans cette étude deux patients ayant des antécédents de TPI qui se sont présentés dans un établissement hospitalier après avoir été victimes d'un AVC aigu et qui ont bénéficié d'activateurs tissulaires du plasminogène par intraveineuse (tPA-IV) et d'une procédure de thrombectomie endovasculaire (TE), ce qui constitue une stratégie de prise en charge inhabituelle pour ce groupe de patients. Nous avons aussi identifié 27 rapports de cas de patients atteints de TPI et victimes d'un AVC ischémique qui n'ont bénéficié ni de tPA ni d'une procédure de TE. De plus, nous nous sommes intéressés à 92 patients gravement atteints de TPI pour lesquels on ne possède aucune donnée en ce qui regarde les causes de leur maladie et qui ont été traités de manière intensive avec des tPA ou au moyen d'une procédure de TE. Chose certaine, il est impossible d'obtenir des preuves concluantes sur la base de ce nombre limité de cas. Des études de cohorte prospectives menées dans plusieurs établissements de santé et portant sur des patients atteints de TPI sont nécessaires dans le futur afin de pouvoir offrir de meilleurs plans de traitement fondés sur des données probantes. À l'heure actuelle, le traitement des AVC ischémiques chez ces patients nécessite la collaboration étroite de spécialistes en hématologie et en neurologie vasculaire afin de trouver un équilibre entre les avantages thérapeutiques et les risques de complications hémorragiques.

Keywords: Immune thrombocytopenia (ITP), Thrombocytopenia, Ischemic stroke, Thrombolysis, Endovascular thrombectomy doi:10.1017/cjn.2020.138

Can J Neurol Sci. 2021; 48: 38-46

Immune thrombocytopenia (ITP) is an autoimmune condition characterized by isolated severe thrombocytopenia. Hemorrhagic tendency is the main manifestation of ITP, but the risk of thrombosis in patients with ITP is thought to be 5\%, predominantly causing venous thromboembolism. ${ }^{1}$ Risk of thrombosis is similar to that associated with malignancy. There is lack of evidence on how to manage acute ischemic stroke and manage secondary prevention in patients with ITP. This is of particular importance as the standard of care for acute ischemic stroke includes a prompt initiation of reperfusion therapies and subsequent use of antiplatelets or anticoagulant agents, which can increase the risk of major bleeding. Concern for potential
From the Department of Medicine, Division of Neurology, University of Alberta, Edmonton, Canada (AA, KP, MA, GB, KB, KK); Department of Medicine, Division of Hematology, University of Alberta, Edmonton, Canada (GA, CW, HLS); Department of Medicine, King Saud University, Riyadh, Saudi Arabia (AA, GA); Department of Medicine, Imam Abdulrahman Bin Faisal University, Dammam, Saudi Arabia (MA); Prince of Wales Clinical School, University of New South Wales, Sydney, Australia (KB); and Department of Radiology \& Diagnostic Imaging, University of Alberta, Edmonton, Canada (JR)

Received April 7, 2020. Final Revisions Submitted June 5, 2020. Date of AcCePtance July 1, 2020.

Correspondence to: Khurshid Khan, University of Alberta, 7-132B Clinical Sciences Building, 1135083 Avenue, Edmonton, AB T6G 2G3, Canada. Email: kakhan@ ualberta.ca 

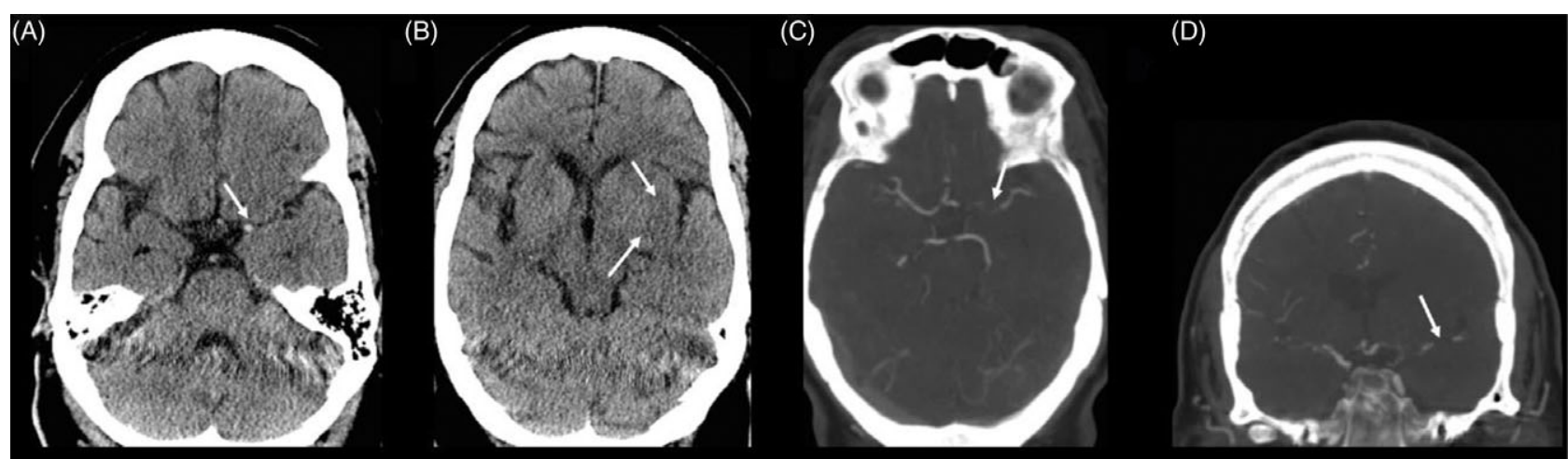

$(\mathrm{E})$

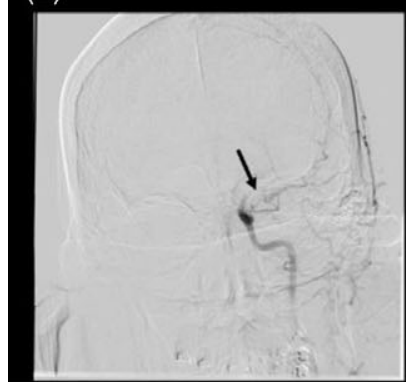

(F)

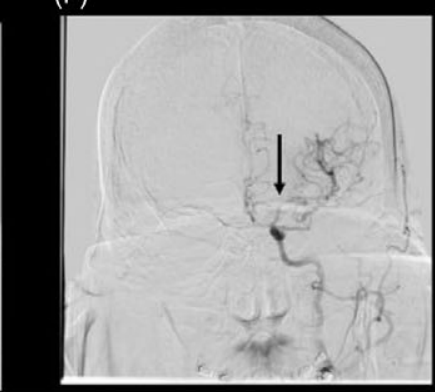

(G)

Figure 1: Diagnostic imaging and therapeutic intervention for the first case reported. (A) Axial CT head shows left MCA hyperdense sign indicating a fresh clot. (B) Axial CT head reveals early ischemic changes in the left insula and basal ganglia as indicated by the arrows. (C and D) Axial and coronal sections of CTA show thrombotic occlusion of the left carotid terminus extending into the left M1 segment of MCA. (E) Digital subtraction angiogram further demonstrates the same finding shown in CTA. (F) Digital subtraction angiogram shows revascularization after a successful endovascular thrombectomy. $(G)$ Diffusion weighted imaging of the brain 24 h after the ischemic stroke reveals a diffusion restriction in the left insula and basal ganglia.

life-threatening hemorrhage in ITP patients influences decisionmaking in acute stroke management.

We present two patients with ITP and acute ischemic stroke who received tissue plasminogen activator (tPA) and endovascular thrombectomy (EVT). In addition, we performed a review of the literature to summarize the available evidence.

\section{Case Series}

\section{Case 1}

A 61-year- old female was brought to hospital after a witnessed sudden onset of right-sided weakness and global aphasia that started $90 \mathrm{~min}$ prior. She had been diagnosed with ITP more than a decade prior to her stroke onset. She had been treated with corticosteroid and intravenous rituximab, and ultimately underwent splenectomy 13 years ago. Despite this, she failed to achieve complete long-term remission. At the time of her stroke she was not on antiplatelet or ITP-specific therapy. Two months prior to stroke onset her platelet count was $28 \times 10^{9} / 1$. Her past medical history included coronary artery disease, dyslipidemia, hypertension, breast cancer in remission for several years, and a remote pulmonary embolism which was managed with an inferior vena cava (IVC) filter and no anticoagulation. Upon arrival to the emergency room, she was in atrial fibrillation (AF) but hemodynamically stable. Her blood pressure was $165 / 80 \mathrm{mmHg}$ and heart rate was 85 beats per minute (bpm). Blood glucose level was $6.5 \mathrm{mmol} / \mathrm{l}(117 \mathrm{mg} / \mathrm{dl})$. Neurological examination revealed drowsiness, global aphasia, and right-sided dense hemiparesis. Her National Institute of Health Stroke Scale (NIHSS) was 16. Computed tomography (CT) of the head demonstrated left middle cerebral artery (MCA) hyperdense sign and early acute ischemic changes within the left basal ganglia and inferior left insula (Figure 1(A) and (B)). CT angiogram (CTA) head and neck showed thrombotic occlusion of the left carotid terminus extending into the left M1 segment of MCA (Figure 1(C) and (D)) with good collaterals and no significant atherosclerotic changes. Her platelets at presentation were $48 \times$ $10^{9} /$. Given the significant neurological deficits, timely presentation to emergency department, and her high prehospitalization functional capacity, the decision was made with the patient's family to proceed with thrombolysis using tPA. This was followed by a single-pass successful EVT using combined approach with stent retriever and aspiration assisted by balloon guide catheter (Figure 1(E) and (F)). The door to successful recanalization time of the thrombolysis in cerebral infarction (TICI) 2B was approximately $120 \mathrm{~min}$. Follow-up CT head after $24 \mathrm{~h}$ showed the expected evolution of ischemic stroke, but there was no hemorrhagic complication. Platelet transfusion was not considered prior to thrombolysis/EVT or required during hospital admission. Four days after thrombolysis and EVT, her NIHSS was 0 and her modified Rankin Score (mRS) was 1 for very mild short-term memory difficulties. While in hospital, she was assessed by hematology and acetylsalicylic acid (ASA) for secondary stroke prevention was recommended, but no specific immunotherapy for ITP was suggested. Further assessment and discussion of risk and benefit of anticoagulation for $\mathrm{AF}$ was 


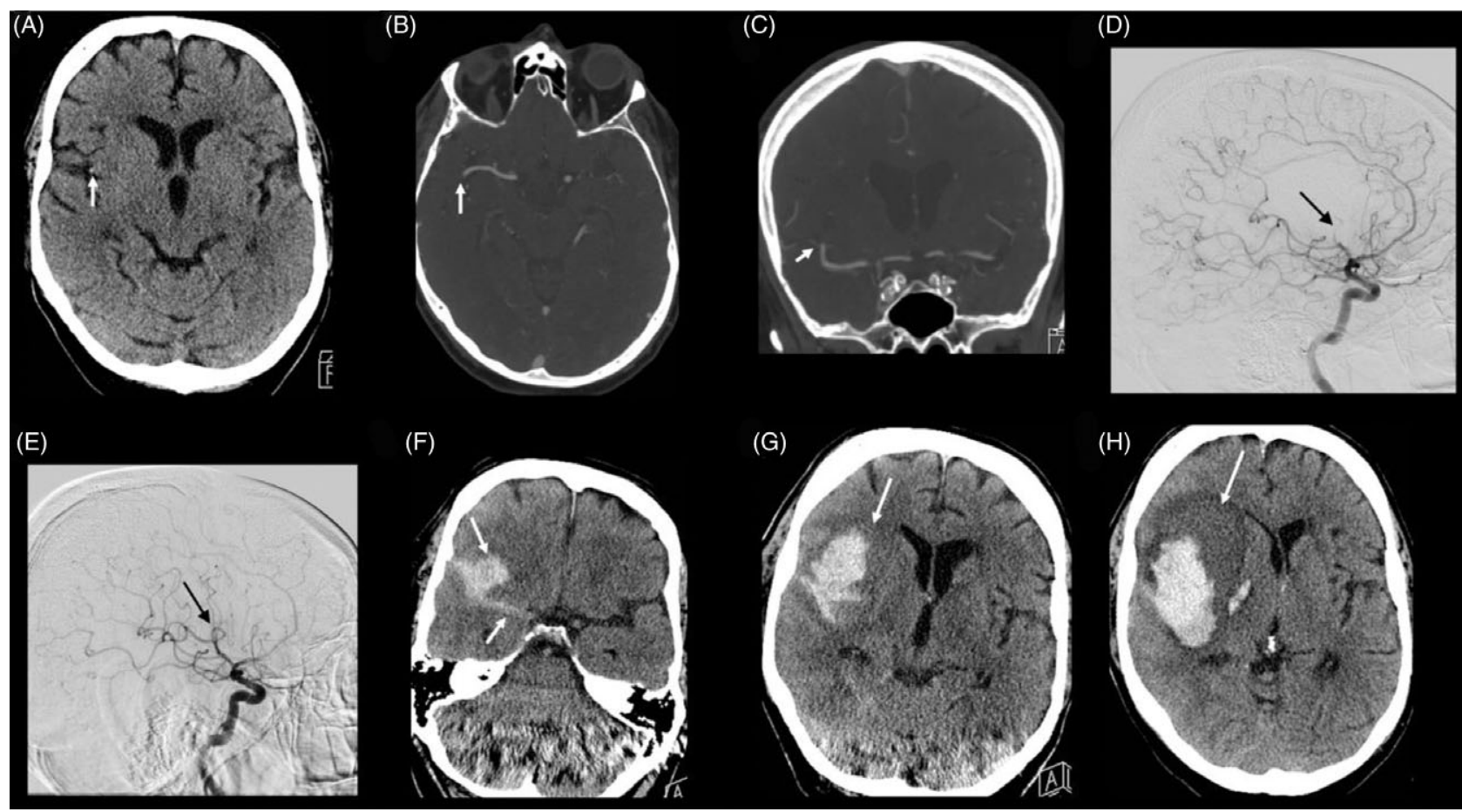

Figure 2: Diagnostic imaging, therapeutic intervention, and follow-up scan for the second case reported. (A) Axial CT head reveals a right distal MCA hyperdense sign in the sylvian fissure correlating with right M2 occlusion. ( $B$ and $C$ ) Axial and coronal CTA show proximal occlusion of M2 segment of the MCA. (D) Digital subtraction angiogram further demonstrates the same finding shown in CTA. (E) Digital subtraction angiogram shows revascularization after a successful EVT. (F, G, and H) Axial CT head after tPA EVT reveals right frontoparietal SAH and large ICH surrounded by edema.

arranged with outpatient hematology after discharge. At 6 months of follow-up, there was no hemorrhagic or thrombotic complication, and her mRS remained 1 . Unfortunately, the patient did not return for hematology follow-up on a number of occasions to assess the risks and benefits of switching ASA to anticoagulation. She was therefore continued on ASA for secondary stroke prevention.

\section{Case 2}

A 75-year-old male was brought to hospital after he was found to have left-sided weakness and slurred speech that started an hour prior. He had been diagnosed with ITP a few years earlier with a remote history of life-threatening gastrointestinal hemorrhage and epistaxis a year ago. The cause of the bleeding was thought to be secondary to critical thrombocytopenia as gastroendoscopic evaluations were negative for malignancy and ulcer. Four months prior to this presentation, he experienced epistaxis with platelet count of $75 \times 10^{9} / 1$. He was treated with corticosteroids and IVIG for ITP 6 months prior, and 2 months prior to presentation underwent splenectomy. His last platelet count was $349 \times 10^{9} / 12$ days before stroke onset. His past medical history also included coronary artery disease, hypertension, and dyslipidemia. At the time of his stroke he was on ASA but not on any ITP-specific therapy. His blood pressure was $175 / 95 \mathrm{mmHg}$ and heart rate was $90 \mathrm{bpm}$. His blood glucose level was $7 \mathrm{mmol} / \mathrm{l}$ $(126 \mathrm{mg} / \mathrm{dl})$. Neurological examination revealed left-sided neglect, right gaze forced deviation, left-sided weakness, decreased sensation, and dysarthria. NIHSS was 14. His CT of the head revealed a right distal MCA hyperdense sign in the sylvian fissure correlating with right M2 occlusion (Figure 2(A)). CTA of the head and neck demonstrated proximal occlusion of M2 segment of the right MCA (Figure 2(B) and (C)) with good collaterals and no significant atherosclerotic changes. Given the significant neurological deficits, the decision was made to proceed with thrombolysis using tPA. He then underwent a single pass successful EVT using combined approach with stent retriever and aspiration assisted by balloon guide catheter (Figure 2(D) and (E)). The door to successful recanalization time of TICI 3 was less than $60 \mathrm{~min}$. He tolerated the procedure well with no immediate complications. Shortly after the procedure, his platelet count result became available, and it was $366 \times 10^{9} / 1$, and his NIHSS improved to 9 . His blood pressure remained stable ranging from $130 / 85$ to $150 / 95$ before and after intervention. He did not require acute antihypertensive therapy. After $2 \mathrm{~h}$ of thrombolysis/EVT, he developed hematemesis, drowsiness, and increasing left-sided weakness. Repeated CT head revealed a right frontoparietal, moderately large, intracerebral hemorrhage (ICH) with some subarachnoid hemorrhage (SAH) (Figure 2(F), $(\mathrm{G})$, and $(\mathrm{H})$ ). His coagulation parameters were within normal range. INR was 1.1 units, PTT was $36 \mathrm{~s}$, and fibrinogen was $3.2 \mathrm{~g} / \mathrm{l}$. In consultation with transfusion medicine, he was given 16 units of cryoprecipitate and one pooled unit of platelets. He was not started on corticosteroid or specific immunotherapy for ITP as it was felt that he was not in ITP relapse. He suffered from additional medical complications, including aspiration pneumonia, congestive heart failure, and AF. Upon discussion with family, goals of care were changed to palliative care and the patient ultimately died. 
Table 1: Clinical, imaging, and therapeutic characteristics in 27 patients reported in the literature with ITP and ischemic stroke

\begin{tabular}{|c|c|c|c|c|c|c|c|c|}
\hline Patient \# & Age & $\begin{array}{c}\text { Platelet } \\
\text { count } \times 10^{9} / 1\end{array}$ & Clinical presentation & Mode of onset & Neuroimaging findings & $\begin{array}{l}\text { Reperfusion or } \\
\text { antithrombotic } \\
\text { therapies }\end{array}$ & $\begin{array}{l}\text { Hemorrhagic } \\
\text { transformation }\end{array}$ & References \\
\hline 1 & 38 & 2 & Hemiparesis & A week & $\begin{array}{l}\text { Multiple cerebral infarctions in the left parietal and } \\
\text { temporal regions. }\end{array}$ & No & No & 39 \\
\hline 2 & 31 & 80 & Hemianopsia & NR & $\begin{array}{l}\text { Right occipital lobe and hippocampal gyrus infarction. } \\
\text { MRA: right PCA infarction }\end{array}$ & Antiplatelet & No & 40 \\
\hline 3 & 41 & 71 & Vertigo, ataxia, diplopia & NR & $\begin{array}{l}\text { Left midbrain infarction. MRA: left superior paramedian } \\
\text { mesencephalic artery }\end{array}$ & Antiplatelet & No & 41 \\
\hline 4 & 31 & 132 & Disoriented & 1 day & $\begin{array}{l}\text { Bifrontal infarctions. MRA: stenosis in bilateral distal } \\
\text { ICAs and MCAs }\end{array}$ & Antiplatelet & No & 42 \\
\hline 5 & 63 & 2 & Hemianopsia & NR & Right occipital infarction & No & No & 43 \\
\hline 6 & 79 & 22 & $\begin{array}{l}\text { Monoparesis, facial } \\
\text { weakness, dysarthria }\end{array}$ & NR & Left periventricular lacunar stroke & $\begin{array}{l}\text { Antiplatelet with platelet } \\
\geq 50\end{array}$ & No & 35 \\
\hline 7 & 43 & 55 & Coma & Acute presentation & $\begin{array}{l}\text { Diffuse supratentorial ischemia, left uncal herniation, } \\
\text { bilateral carotid arteries occlusion, and thrombus } \\
\text { within the basilar artery }\end{array}$ & No & No & 44 \\
\hline 8 & 33 & 84 & Hemiparesis, dysarthria & Acute presentation & $\begin{array}{l}\text { Right insular infarction. MRA: Distal right ICA } \\
\text { occlusion }\end{array}$ & $\begin{array}{l}\text { IA urokinase and IV } \\
\text { heparin }\end{array}$ & No & 3 \\
\hline 9 & 64 & 17 & Hemiparesis, aphasia & Acute presentation & $\begin{array}{l}\text { Left MCA infarction and hemorrhagic transformation. } \\
\text { MRA: Left ICA occlusion }\end{array}$ & Antiplatelet & $\begin{array}{l}\text { Yes (Found at the baseline } \\
\text { scan) }\end{array}$ & 45 \\
\hline 10 & 58 & 18 & Vertigo, ataxia & 1 day & $\begin{array}{l}\text { Left cerebellar vermis infarction and hemorrhagic } \\
\text { transformation }\end{array}$ & Antiplatelet & $\begin{array}{l}\text { Yes (found at the baseline } \\
\text { scan) }\end{array}$ & 46 \\
\hline 11 & 84 & 40 & $\begin{array}{l}\text { Aphasia, sensory } \\
\text { disturbance, dysarthria }\end{array}$ & Acute presentation & left thalamic infarction & No & No & 47 \\
\hline 12 & 46 & 20 & $\begin{array}{l}\text { Hemiparesis, dysarthria, } \\
\text { hemianopsia }\end{array}$ & $10 \mathrm{~h}$ & $\begin{array}{l}\text { Right MCA territory infarction. MRA: right MCA } \\
\text { occlusion }\end{array}$ & Antiplatelet & No & 48 \\
\hline 13 & 60 & 20 & Hemiparesis, dysarthria & A day & Left MCA border zone infarctions & Antiplatelet & No & 49 \\
\hline 14 & 51 & 270 & NR & NR & Left frontal and parietal lobes infarction & Antiplatelet & No & 50 \\
\hline 15 & 33 & 51 & NR & NR & Right SCA territory infarction & Antiplatelet & No & 50 \\
\hline 16 & 30 & 119 & NR & $\mathrm{NR}$ & Right MCA territory infarction with cortical involvement & Antiplatelet & No & 50 \\
\hline 17 & 49 & 39 & NR & NR & Left MCA subcortical infarction & $\begin{array}{c}\text { Antiplatelet and } \\
\text { anticoagulation }\end{array}$ & No & 50 \\
\hline 18 & 75 & 226 & NR & NR & Bilateral hemispheric infarctions & Anticoagulation & No & 50 \\
\hline 19 & 72 & 182 & NR & NR & $\begin{array}{l}\text { Left centrum semiovale infarction. MRA: Left ICA } \\
\text { occlusion }\end{array}$ & $\begin{array}{c}\text { Antiplatelet and } \\
\text { anticoagulation }\end{array}$ & No & 50 \\
\hline 20 & 49 & 43 & NR & NR & $\begin{array}{l}\text { Right MCA territory infarction. MRA: Distal right MCA } \\
\text { occlusion }\end{array}$ & Anticoagulation & No & 50 \\
\hline 21 & 36 & 6 & Vertigo & $\begin{array}{l}\text { Paroxysmal transient } \\
\text { episodes }\end{array}$ & $\begin{array}{l}\text { Right cerebellar and vermis infarction. MRA: Right } \\
\text { vertebral artery stenosis }\end{array}$ & No & No & 38 \\
\hline
\end{tabular}




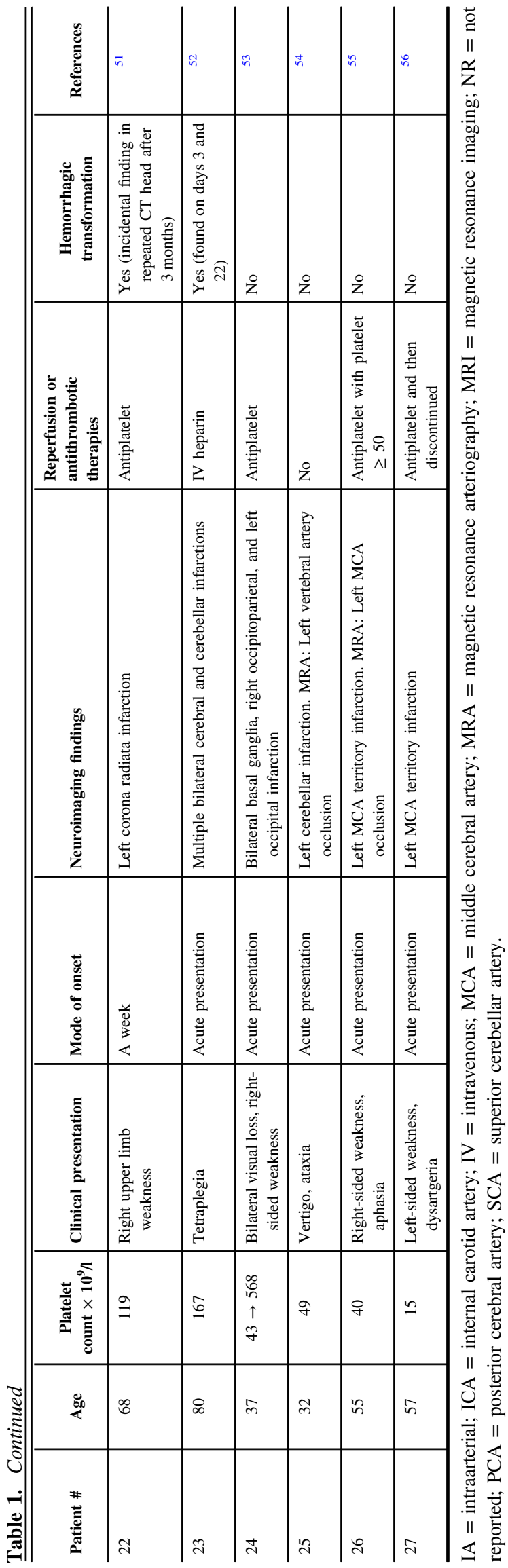

\section{Discussion}

\section{Summary of Reported Cases}

The incidence of ITP in the general population is estimated to be 2 to 5 per 100,000 people. $^{2}$ A literature review reveals 27 case reports relating to ischemic stroke in patients with ITP (Table 1). Most of those patients had at least one vascular risk factor in addition to their ITP disorder. The mode of onset in all cases varied between acute and subacute presentations. None of the patients received thrombolysis or an endovascular procedure except a single report of intraarterial urokinase given to a patient with ischemic stroke with platelet count of $84 \times 10^{9} / 1$. ${ }^{3}$ More than half of the patients were started on antiplatelet for acute management and/or secondary prevention. Hemorrhagic transformation (HT) occurred in four patients, three of them were on antiplatelets and one was on anticoagulation. Two of the patients who developed HT had significant thrombocytopenia and the other two had a platelet count $>100 \times 10^{9} / 1$.

\section{Mechanism of Thrombosis}

The general pathophysiology of ITP is that of an acquired autoimmune disorder, which can be primary or secondary, causing platelet destruction and impaired production. ${ }^{2}$ Multiple hypotheses have been proposed to explain the mechanism of thrombosis in patients with ITP. The current leading hypothesis revolves around platelet microparticles (PMPs). PMPs are secreted by both activated and destroyed platelets as they are the natural elements that promote thrombosis for hemostatic control, but they also may, in part, be responsible for pathological thrombosis in patients with ITP. Compared to healthy controls, elevated levels of PMPs are detected in patients with ITP and concurrent ischemic events. ${ }^{4}$ Elevated levels of PMPs have also been found in patients with ITP and vascular dementia due to ischemic small vessel disease - these patients also had higher platelet counts as well as more often had splenectomy. ${ }^{5}$ PMPs are not alone to blame for thrombosis in ITP; it is thought that during immunerelated platelet destruction there is a large proportion of immature activated platelets released from bone marrow, as well as large platelet-leukocyte-monocyte aggregates circulating and endothelium activating antibodies which all contribute to an increased risk of thrombosis. ${ }^{1,3,5,6}$ Physiological nitric oxide (NO) in vessel endothelium in healthy individuals prevents platelet adhesion to vessel walls, and it is possible that in ITP, NO is depleted as a consequence of immune activation and also contributes to the prothrombotic state in ITP. ${ }^{1,7}$ Neither of the patients presented in our case series were actively receiving intravenous immunoglobulin (IVIG) to treat their ITP, but IVIG is a known prothrombotic medication. Both of our patients had undergone splenectomy, which has consistently been shown to cause 2 times the risk of venous thromboembolism than the general population, and an insignificant increased risk of arterial thrombosis. ${ }^{8}$ In our cases, we cannot be certain about the exact mechanism of ischemic stroke as both of them had AF and conventional vascular risk factors in addition to their ITP condition.

\section{Clinical Decision-Making}

We faced a management dilemma for our two patients given the insufficient data that represent the outcome of patients with ITP and ischemic stroke. Patients with significant thrombocytopenia $\left(<100 \times 10^{9} / 1\right)$ are already at increased risk of major 
bleeding and have been uniformly excluded from all major acute ischemic stroke clinical trials. The paucity of data surrounding the outcomes of these patients makes it difficult to weigh the risks and benefits of potentially lifesaving and disability-preventing therapies. Specific data related to the risk of bleeding after thrombolysis in patients with ischemic stroke and ITP are lacking. In general, the 5-year cumulative rate of spontaneous ICH in adult ITP patients is $1.4 \%$ which is 3 times higher than patients without ITP; however, all patients with reported spontaneous ICH had platelets of equal to or greater than $30 \times 10^{9} / 1 .^{9,10}$ There are other factors than ITP that increase the risk of intracerebral bleeding postreperfusion. AF, elevated blood pressure, taking an antiplatelet agent prior to EVT and thrombolysis, and statin use have all been associated with higher risks of symptomatic HT. ${ }^{11}$ We cannot establish that the cause of postreperfusion ICH in our second patient was due to ITP. He had multiple additional factors other than his ITP including the fact he was on an antiplatelet agent at presentation, had a new diagnosis of AF, and a history of past severe bleeding events. ITP may have contributed to his risk for bleeding despite having normal platelet count.

\section{Acute Stroke Therapy in Patient with ITP}

\section{The use of thrombolysis in patients with ITP}

The American Heart Association/American Stroke Association (AHA/ASA) guideline recommended that tPA for patients with acute stroke and a clinical history of potential bleeding diathesis may be considered on a case-by-case basis because the safety and efficacy of tPA in this situation is unknown. ${ }^{12,13}$ Significant thrombocytopenia regardless of the cause is considered a relative contraindication for IPA for acute ischemic stroke per AHA/ASA and the Canadian Stroke Best Practice Recommendations guidelines. ${ }^{12,14}$ The relationship between platelet count and hemorrhage risk is unknown. There have been no randomized trials or prospective studies to evaluate the risk of hemorrhage in patients with acute ischemic stroke and significant thrombocytopenia. The threshold of $<100 \times 10^{9} / 1$ for platelets being a contraindication for thrombolysis was derived from an expert panel consensus. In a study that looked at patients in the Thrombolysis in Stroke Patients (TRISP) registry, among 7,533 tPA-treated stroke patients, 44 had significant thrombocytopenia $\left(<100 \times 10^{9} / l\right) .{ }^{15}$ Three patients $(6.8 \%)$ developed symptomatic ICH (sICH) using the Second European Cooperative Acute Stroke Study (ECASS II) criteria. ${ }^{16}$ In the same study, the overall risks of sICH, poor functional outcome, and mortality did not differ significantly from those patients with a platelet count $>100$ $\times 10^{9} / \mathrm{l}$. It was found that every decrease in platelet count by $10,000 / 1$ increased the risk of sICH by $2-5 \%$, yet this was not associated with poor outcome or mortality. In addition, there are 27 patients in multiple studies and case reports who received tPA with significant thrombocytopenia. ${ }^{17-22}$ The detailed information about the cause of thrombocytopenia was not available in most cases. Two of these patients (7.7\%) developed sICH. By compiling patients from all the studies, the risk sICH in significant thrombocytopenia post-tPA is $7 \%$. Although the sample size is very small, the rate is not significantly different than $\mathrm{sICH}$ in patients with normal platelet counts treated with tPA. In in vitro studies, tPA has shown to inhibit platelet aggregation, but does not affect platelet activation, and perhaps the reports of bleeding post-tPA in individuals with ITP are not as high as expected. ${ }^{23}$ This further challenges the justification of withholding thrombolysis for platelet counts $<100 \times 10^{9} / \mathrm{l}$. However, in ITP platelets may be dysfunctional for other reasons as discussed previously.

\section{Performing EVT for patients with ITP}

Similar to tPA, a specific data related to the safety of EVT in patients with ischemic stroke and ITP is lacking. Although EVT without thrombolysis in patients with ITP who present with the acute ischemic stroke and large vessel occlusion may be a safer option, the experience with EVT alone in these patients is also limited. Lower thresholds for thrombocytopenia regardless of the cause were used in the EVT studies, such as (Multi - MERCII: $<30 \times 10^{9} /$ l, MR-CLEAN: $<40 \times 10^{9} /$ l, SWIFT PRIME and EXTEND IA: $<100 \times 10^{9} / 1$, DAWN and DEFUSE-3: $<50 \times 10^{9} /$ l) ${ }^{24-29}$ In the MERCI/Multi MERCI cohort, EVT was used in six patients with significant thrombocytopenia. ${ }^{30}$ Symptomatic ICH was noted in one patient (platelet count was $16 \times 10^{9} /$ ), mild SAH in another patient (platelet count was $\left.64 \times 10^{9} / 1\right)$, and four patients did not develop any hemorrhagic complications (platelets counts were $37-94 \times 10^{9} / 1$ ). A recently published retrospective observational analysis from a single center has assessed the EVT in patients with thrombocytopenia. ${ }^{31}$ Fifteen patients with significant thrombocytopenia underwent EVT. The information for the cause of thrombocytopenia in each individual was not available. Symptomatic ICH occurred in one patient with no groin bleeding complication in any patients.

There are many factors that need to be considered when deciding to proceed with thrombolysis and EVT in patients with acute stroke. This includes premorbid functional status, presence of other medical comorbidities, severity of stroke, goals of care, and timely access to different therapeutic options. If patients are known to have ITP, consideration to the stability of the disease, last known platelet count and time of last seen well should be taken into account prior to initiating acute stroke therapy. It is reasonable to wait prior to initiating any therapy for the platelet count to return in patients who have active disease, have clinical stigmata of thrombocytopenia, or their most recent platelet count prior to presentation was $<100 \times 10^{9} / 1$. In patients who present within the thrombolysis window but who are felt not to be eligible for thrombolysis, or who are outside the window, they should be considered for EVT. If a patient is known to have ITP or who has recent unexplained low platelet count, urgent consultation with hematology is recommended prior to proceeding with any therapies, and decisions should be made in collaboration with stroke clinicians, hematologists, the patients and their families where possible.

\section{The use of antiplatelet and anticoagulation agents in patients with ITP}

Data on the use of antiplatelet and anticoagulation in ITP for ischemic stroke are lacking; thus, the strategy for stroke prevention should be individualized according to the stroke mechanism, comorbidities, and risk of hemorrhagic complications. No direct 
evidence exists to recommend a platelet threshold for safe antiplatelet or anticoagulant use, but a survey of International ITP experts reported a threshold of platelets $>50 \times 10^{9} / 1$ for the use of both antiplatelets and anticoagulants in acute and longterm situations. ${ }^{32}$ This value is also accepted in the cardiology literature as they suggest using dual antiplatelet therapy with clopidogrel and aspirin after stenting provided platelets are at least $>50 \times 10^{9} / 1 .^{33}$ If antithrombotic agents are indicated for acute or long term, a platelet count of $>50 \times 10^{9} / 1$ is recommended, and to hold them if platelet counts drop below this. ${ }^{33-35}$ In vitro studies have shown that both aspirin and $\mathrm{P}_{2} \mathrm{Y}_{12}$ inhibitors are able to block the prothrombotic effects of PMP, and thus either could be used in primary and secondary prevention. The stroke guidelines currently suggest aspirin as first line for secondary prevention. ${ }^{36}$ The decision for long-term antiplatelet and anticoagulation treatment should be individualized and take into account the presence or absence of other stroke risk factors.

A therapeutic algorithm for patients with ITP and thrombotic complications has been proposed. ${ }^{34}$ Anticoagulation is not recommended if there is a life-threatening hemorrhage or hemorrhage that requires transfusion (WHO grade III/IV). Corticosteroid and IVIG may be administered to increase the platelet count to a safe level $\geq 50 \times 10^{9} / 1$ before starting anticoagulation or antiplatelet agents. Case reports of patients with ITP and acute stroke have demonstrated that if a stroke is deemed to be caused by ITP, and a decision for acute stroke therapy has been proposed, immunosuppressing agents such as IVIg and corticosteroids can safely be initiated in the acute phase of stroke, the thrombopoietin receptor agonists (TPO-RAs) can also be considered in place of immunosuppressants to increase platelet counts. ${ }^{35,37,38}$ Furthermore, thrombopoietin receptor agonists can be given to maintain the level of platelets. The therapeutic dose of anticoagulation can be considered for ITP patients with no hemorrhage, stable hemoglobin $=\mathrm{WHO}$ grade $0 / \mathrm{I} / \mathrm{II}$ and platelet count $\geq 50 \times 10^{9} / 1$. There is no specific data for direct oral anticoagulation (DOAC) in this context.

\section{Conclusion}

We presented two patients with ITP and acute ischemic strokes who were treated with thrombolysis and EVT. In the literature, there are 27 patients with ITP who presented with acute ischemic stroke, and only one of them was treated with acute reperfusion therapy. In addition, there are 92 patients with significant thrombocytopenia with no available data regarding the cause of thrombocytopenia, who were acutely treated $(\mathrm{tPA}=71, \quad \mathrm{EVT}=21)$. Seven patients developed sICH $(\mathrm{tPA}=5, \mathrm{EVT}=2)$, and one patient underwent EVT developed mild SAH. A conclusion cannot be drawn based on these limited number of published cases and with the lack of detailed information about the etiology of the thrombocytopenia. Treatment of acute ischemic stroke in patients with ITP requires close collaboration between hematology and vascular neurology experts to find a balance between the benefit and risk of hemorrhagic complications. Guidelines are lacking for acute stroke and stroke prevention management in ITP patients. Given the pathology of ITP thrombocytopenia is unique, patients with ITP cannot simply be included in groups of patients with thrombocytopenia due to other causes. Future stroke studies, such as multicenter prospective cohort study, that include ITP patients and patients with thrombocytopenia are needed to provide evidence-based treatment plans.

\section{ACKNOWLEDGMENT}

AA thanks King Saud University and the Saudi Arabian Ministry of Education for Residency and Fellowship funding. AA thanks The University of Alberta Hospital Foundation and the Neuroscience and Mental Health Institute for the Neurology Fellowship Award.

\section{Disclosures}

$\mathrm{KB}$ reports grants and personal fees from Pfizer, personal fees from Boehringer-Ingleheim, grants and personal fees from Servier, personal fees from Medtronic, outside the submitted work. CW is a member of advisory boards and honoraria: Pfizer, BMS-Pfizer, Leo-Pharma, Servier. Dr. Wu is a local Principal Investigator for trials with funding from: Bayer, Daiichi-Sankyo, CIHR, Heart and Stroke Foundation of Canada. The other authors have no conflicts of interest to declare.

\section{Statement of Authorship}

AA conceived of the idea, acquired the data, contributed to the medical management of the patients, and drafted the initial manuscript. KP, MA, GA, CW, and HLS made critical revisions of the manuscript. GB, KB, and JR contributed to the medical management of the patients and made critical revisions of the manuscript. KK conceived of the idea and made critical revisions of the manuscript.

\section{REFERENCES}

1. Thachil J, Callaghan T, Martlew V. Thromboembolic events are not uncommon in patients with immune thrombocytopenia. $\mathrm{Br} \mathrm{J}$ Haematol. 2010;150(4):496-7.

2. Neunert C, Terrell DR, Arnold DM, Buchanan G, Cines DB, Cooper N, et al. American society of hematology 2019 guidelines for immune thrombocytopenia. Blood Adv. 2019;3(23): 3829-66.

3. Rhee HY, Choi HY, Kim SB, Shin WC. Recurrent ischemic stroke in a patient with idiopathic thrombocytopenic purpura. J Thromb Thrombolys. 2010;30(2):229-32.

4. Jy W, Horstman LL, Arce M, Ahn YS. Clinical significance of platelet microparticles in autoimmune thrombocytopenias. J Lab Clin Med. 1992;119(4):334-45.

5. Ahn YS, Horstman LL, Jy W, Jimenez JJ, Bowen B. Vascular dementia in patients with immune thrombocytopenic purpura. Thromb Res. 2002;107(6):337-44.

6. Aledort LM, Hayward CP, Chen MG, Nichol JL, Bussel J, Group ITPS. Prospective screening of 205 patients with ITP, including diagnosis, serological markers, and the relationship between platelet counts, endogenous thrombopoietin, and circulating antithrombopoietin antibodies. Am J Hematol. 2004;76(3):205-13.

7. Freedman JE, Loscalzo J. Nitric oxide and its relationship to thrombotic disorders. J Thromb Haemost. 2003;1(6):1183-8.

8. Rodeghiero F. A critical appraisal of the evidence for the role of splenectomy in adults and children with ITP. Br J Haematol. 2018;181(2):183-95.

9. Norgaard M, Jensen AO, Engebjerg MC, Farkas DK, Thomsen RW, Cha S, et al. Long-term clinical outcomes of patients with primary chronic immune thrombocytopenia: a danish population-based cohort study. Blood. 2011;117(13):3514-20.

10. Neunert C, Noroozi N, Norman G, Buchanan GR, Goy J, Nazi I, et al. Severe bleeding events in adults and children with primary 
immune thrombocytopenia: a systematic review. J Thromb Haemost. 2015;13(3):457-64.

11. van Kranendonk KR, Treurniet KM, Boers AMM, Berkhemer OA, van den Berg LA, Chalos V, et al. Hemorrhagic transformation is associated with poor functional outcome in patients with acute ischemic stroke due to a large vessel occlusion. J Neurointerv Surg. 2019;11(5):464-8.

12. Powers WJ, Rabinstein AA, Ackerson T, Adeoye OM, Bambakidis $\mathrm{NC}$, Becker K, et al. Guidelines for the early management of patients with acute ischemic stroke: a guideline for healthcare professionals from the American Heart Association/American Stroke Association. Stroke. 2018;49(3):e46-110.

13. Demaerschalk BM, Kleindorfer DO, Adeoye OM, Demchuk AM, Fugate JE, Grotta JC, et al. Scientific rationale for the inclusion and exclusion criteria for intravenous alteplase in acute ischemic stroke: a statement for healthcare professionals from the American Heart Association/American Stroke Association. Stroke. 2016;47(2):581-641.

14. Boulanger JM, Lindsay MP, Gubitz G, Smith EE, Stotts G, Foley N, et al. Canadian stroke best practice recommendations for acute stroke management: prehospital, emergency department, and acute inpatient stroke care, 6th edition, update 2018. Int J Stroke. 2018;13(9):949-84.

15. Gensicke H, Al Sultan AS, Strbian D, Hametner C, Zinkstok SM, Moulin S, et al. Intravenous thrombolysis and platelet count. Neurology. 2018;90(8):e690-7.

16. Hacke W, Kaste M, Fieschi C, von Kummer R, Davalos A, Meier D, et al. Randomised double-blind placebo-controlled trial of thrombolytic therapy with intravenous alteplase in acute ischaemic stroke (ECASS II). Second European-Australasian acute stroke study investigators. Lancet. 1998;352(9136):1245-51.

17. Frank B, Grotta JC, Alexandrov AV, Bluhmki E, Lyden P, Meretoja A, et al. Thrombolysis in stroke despite contraindications or warnings? Stroke. 2013;44(3):727-33.

18. Kvistad CE, Logallo N, Thomassen L, Waje-Andreassen U, Brogger J, Naess H. Safety of off-label stroke treatment with tissue plasminogen activator. Acta Neurol Scand. 2013;128(1): $48-53$.

19. Meretoja A, Putaala J, Tatlisumak T, Atula S, Artto V, Curtze S, et al. Off-label thrombolysis is not associated with poor outcome in patients with stroke. Stroke. 2010;41(7):1450-8.

20. Mowla A, Kamal H, Lail NS, Vaughn C, Shirani P, Mehla S, et al. Intravenous thrombolysis for acute ischemic stroke in patients with thrombocytopenia. J Stroke Cerebrovasc Dis. 2017;26(7): 1414-8.

21. Brunner F, Tomandl B, Schroter A, Mellinghoff C, Haldenwanger $\mathrm{A}$, Hildebrandt $\mathrm{H}$, et al. Hemorrhagic complications after systemic thrombolysis in acute stroke patients with abnormal baseline coagulation. Eur J Neurol. 2011;18(12):1407-11.

22. Bragin I, Chen JM. A case report of recombinant tissue plasminogen activator use in a SPAN-100-Positive geriatric patient with thrombocytopenia. Cureus. 2017;9(12):e1933.

23. Lu J, Hu P, Wei G, Luo Q, Qiao J, Geng D. Effect of alteplase on platelet function and receptor expression. J Int Med Res. 2019;47(4):1731-9.

24. Smith WS, Sung G, Saver J, Budzik R, Duckwiler G, Liebeskind DS, et al. Mechanical thrombectomy for acute ischemic stroke: final results of the multi MERCI trial. Stroke. 2008;39(4):1205-12.

25. Fransen PS, Beumer D, Berkhemer OA, van den Berg LA, Lingsma $\mathrm{H}$, van der Lugt A, et al. MR CLEAN, a multicenter randomized clinical trial of endovascular treatment for acute ischemic stroke in the Netherlands: study protocol for a randomized controlled trial. Trials. 2014;15:343.

26. Saver JL, Goyal M, Bonafe A, Diener HC, Levy EI, Pereira VM, et al. Stent-Retriever thrombectomy after intravenous t-PA vs. t-PA alone in stroke. N Engl J Med. 2015;372(24):2285-95.

27. Campbell BC, Mitchell PJ, Kleinig TJ, Dewey HM, Churilov L, Yassi $\mathrm{N}$, et al. Endovascular therapy for ischemic stroke with perfusionimaging selection. N Engl J Med. 2015;372(11):1009-18.

28. Nogueira RG, Jadhav AP, Haussen DC, Bonafe A, Budzik RF, Bhuva P, et al. Thrombectomy 6 to 24 hours after stroke with a mismatch between deficit and infarct. $\mathrm{N}$ Engl $\mathrm{J}$ Med. 2018;378(1):11-21.
29. Albers GW, Marks MP, Kemp S, Christensen S, Tsai JP, OrtegaGutierrez S, et al. Thrombectomy for stroke at 6 to 16 hours with selection by perfusion imaging. $\mathrm{N}$ Engl J Med. 2018;378(8):708-18

30. Nogueira RG, Smith WS, MERCI and Multi MERCI Writing Committee. Safety and efficacy of endovascular thrombectomy in patients with abnormal hemostasis: pooled analysis of the MERCI and multi MERCI trials. Stroke. 2009;40(2):516-22.

31. Desai SM, Mehta A, Morrison AA, Gross BA, Jankowitz BT, Jovin TG, et al. Endovascular thrombectomy, platelet count, and intracranial hemorrhage. World Neurosurg. 2019;127:e1039-e43.

32. Pishko AM, Misgav M, Cuker A, Cines DB, George JN, Vesely SK, et al. Management of antithrombotic therapy in adults with immune thrombocytopenia (ITP): a survey of ITP specialists and general hematologist-oncologists. J Thromb Thrombolysis. 2018;46(1):24-30.

33. McCarthy CP, Steg G, Bhatt DL. The management of antiplatelet therapy in acute coronary syndrome patients with thrombocytopenia: a clinical conundrum. Eur Heart J. 2017;38(47):3488-92.

34. Matzdorff A, Beer JH. Immune thrombocytopenia patients requiring anticoagulation-maneuvering between scylla and charybdis. Semin Hematol. 2013;50(Suppl 1):S83-8.

35. Mahawish K, Pocock N, Mangarai S, Sharma A. Cerebral infarction in idiopathic thrombocytopenic purpura: a case report. BMJ Case Rep. 2009;2009.

36. Giacomazzi A, Degan M, Calabria S, Meneguzzi A, Minuz P. Antiplatelet agents inhibit the generation of platelet-derived microparticles. Front Pharmacol 2016;7:314.

37. Mihalov J, Timarova G. A seeming paradox: ischemic stroke in the context of idiopathic thrombocytopenic purpura. Clin Appl Thromb Hemost. 2016;22(2):115-20.

38. Zhao HM, Lian YJ, Zhang HF, Xie NC, Gao YL, Wang ZY, et al. Ischemic stroke associated with immune thrombocytopenia. J Thromb Thrombolys. 2015;40(2):156-60.

39. Otsuki T, Funakawa T, Sugihara T, Kanzaki A, Wada H, Inoue T, et al. Multiple cerebral infarctions in a patient with refractory idiopathic thrombocytopenic purpura. J Intern Med. 1997;241(3): 249-52.

40. Nanri K, Niiyama K, Utsumi H, Sekine S, Katou H, Kougo K, et al. A case of migrainous infarction accompanying idiopathic thrombocytopenic purpura. Rinsho Shinkeigaku. 2002;42(9):868-72.

41. Tsuda H, Shinozaki Y, Tanaka K, Ohashi K. Divergence paralysis caused by acute midbrain infarction. Intern Med. 2012;51(22): 3169-71.

42. Yunoki M, Suzuki K, Uneda A, Okubo S, Hirashita K, Yoshino K. Multiple cerebral infarctions in a patient with idiopathic thrombocytopenic purpura. Iran J Neurol. 2016;15(3):177-9.

43. Theeler BJ, Ney JP. A patient with idiopathic thrombocytopenic purpura presenting with an acute ischemic stroke. J Stroke Cerebrovasc Dis. 2008;17(4):244-5.

44. Modrykamien A, Reddy A, Guzman JA, Farha S. Massive cerebrovascular infarct due to the catastrophic antiphospholipid syndrome in a patient with idiopathic thrombocytopenic purpura. J Intensive Care Med. 2009;24(4):269-72.

45. Phan TG, Owen R. Paradoxical ischaemic stroke in the setting of idiopathic thrombocytopenic purpura. Intern Med J. 2011;41(8): 643-4.

46. Choi WJ, Kim MJ, Kim C, Sohn JH, Choi HC. Acute cerebellar infarction associated with intravenous gammaglobulin treatment in idiopathic thrombocytopenic purpura. J Stroke Cerebrovasc Dis. 2012;21(8):917, e9-11.

47. De La Pena A, Fareed J, Thethi I, Morales-Vidal S, Schneck MJ, Shafer D. Ischemic stroke in the setting of chronic immune thrombocytopenia in an elderly patient-a therapeutic dilemma. Clin Appl Thromb Hemost. 2012;18(3):324-6.

48. Kim H, Hwang SS, Uh Y, Kim J, Yoon KJ, Lee JY. A case associated with comorbidities among cerebral infarction, idiopathic thrombocytopenic purpura, and triple $\mathrm{x}$ syndrome. Turk $\mathrm{J}$ Haematol. 2014;31(2):184-7.

49. Ichijo M, Ishibashi S, Ohkubo T, Nomura S, Sanjo N, Yokota T, et al. Elevated platelet microparticle levels after acute ischemic stroke with concurrent idiopathic thrombocytopenic purpura. J Stroke Cerebrovasc Dis. 2014;23(3):587-9. 
50. Park HK, Lee SH. Ischemic stroke associated with immune thrombocytopenia: lesion patterns and characteristics. Neurol Sci. 2014;35(11):1801-6.

51. Ong CY, Vasanwala FF. Thrombotic paradox: ischaemic stroke in immune thrombocytopaenia. A case report and review. Cureus. 2017;9(12):e1904.

52. Sasaki T, Yasuda T, Abe D, Miyano R, Kainaga M, Tomura N, et al. A case of multiple cerebral infarction preceding acute exacerbation of idiopathic thrombocytopenic purpura. J Stroke Cerebrovasc Dis. 2019;28(3):789-91.

53. Wang WT, Li YY, Lin WC, Chen JY, Lan KM, Sun CK, et al. Bilateral visual loss and cerebral infarction after spleen embolization in a trauma patient with idiopathic thrombocytopenic purpura: a case report. Medicine (Baltimore). 2018;97(16): $\mathrm{e} 0332$.

54. Hindi Z, Onteddu N, Ching CA, Khaled AA. Vertebral artery thrombosis in chronic idiopathic thrombocytopenic purpura. Case Rep Hematol. 2017;2017:3184346.

55. Gümüş H, Yilmaz H. Severe ischemic stroke in a patients with idiopathic thrombocytopenic purpura: a case report. Turk J Phys Med Rehab. 2015;61(2):171-4.

56. Imranullah Hashmi AMB. Ischaemic stroke in a patient with refractory idiopathic thrombocytopenic purpura: an unusual clinical dilemma. J Med Cases. 2012;3(3):204-6. 